\title{
A magnificent seven
}

\section{Of the 325 News and Views articles published this year, seven are singled out for special attention. They illustrate the great job that scientists can do in communicating and commenting on new research.}

$\mathrm{O}$ ne of the duties of an editor on a scientific publication is to take a succinct, clear and informative piece of writing and, through the leaden application of house rules, turn it into unreadable porridge. That's the view of the sceptical scientist and there's occasional truth in the observation. The better - and less wearing - editorial course for such an article is simply to publish it, tweaked little, if at all. Writers of such pieces are to be treasured by editors and readers alike.

Hence this celebration of seven authors who wrote outstanding News and Views articles for Nature in 2003: David Wark, Philip N. Benfey, S. Blair Hedges, Steve Blinkhorn, John Harte, Toren Finkel and Len A. Fisk. This is a competition that the contenders did not enter. Invidious though it is in that circumstance to choose between very fine and fine examples of exposition, the first three are winners and the other four 'highly commended'. The authors have respectively earned themselves magnums and bottles of champagne.

The seven have been chosen not by a panel of the great and the good in science, but by the three News and Views editors at Nature. The thinking behind that stems from a sceptic's view from the editing side of the fence. It is not clear from a published article how much of the structure and prose, good or bad, is due to the author and how much to the editor. True, cer- tain scientists become justifiably well known for the clarity of their writing. But when the object to be gauged is communication of content, as much as content itself, a judgement of any given article cannot really be made except from its raw form.

Thus the choice of judges, who also came cheaply. And thus the choice of these seven articles, which were published much as written. From a short list of 30 or so, seven displayed the relevant qualities (a number that also makes for an eye-catching title).

News and Views articles, and similar writing in other journals, occupy unusual publishing ground. In both style and content, they lie between journalism and the scientific review literature. Sometimes the principles of the two conflict. But when liveliness and expert opinion come together well, they make for a very happy combination. Over the years there have been some fine and prolific exponents, such as Robert May (now president of the Royal Society) and Jared Diamond (a Pulitzer prizewinner).

The News and Views section first appeared in Nature in the issue of 2 January 1926, but curiously enough as 'Views and News'. There was evidently a quick rethink, because in the next issue the words were swapped into their more logical order. Only in the mid-1960s, however, did the section take its modern form, the hallmark being scientists writing about the work of other scientists in newsy fashion. Of the star authors featured here, five were commenting on papers published in Nature, and two on work that appeared elsewhere. Their articles have a variety of virtues. One is to engage the reader from the beginning. A second is the effective use of metaphor or analogy. A third is a certain narrative thread, avoiding discursive detail. A fourth is explaining technicalities, where essential, and avoiding them where not. And a fifth is the appropriate visual support from graphics or photos.

All this is good as far as it goes, but each of these pieces offers more. They provide context and opinion on the work under discussion, so living up to the second part of the apparently cutesy name of News and Views. Context and opinion come in the form of ideas for further investigation, comparison with other bodies of evidence or theory, and comment on the limitations of the new work. Such critical appraisal is a central service offered by authors writing for a broad scientific public — or any public, come to that.

Congratulations and thanks to this particular magnificent seven. But thanks, too, to all of the other writers who have taken the time and trouble to produce News and Views articles in 2003. Once the hangover from the holiday season is over, we look forward to more of the same in 2004.

Timlincoln

\section{Champagne writing}

These articles can be seen at www.nature.com/nature/newsandviews/magnificent7

ODavid Wark "Particle physics: Now you see them, now you don't" (421, 485-486)

Readable and thoughtful account of the latest evidence that types of neutrino can interchange. Holds the attention despite its length.

OPhilip N. Benfey "Molecular biology: MicroRNA is here to stay" (425, 244-245)

Goes beyond the main paper under discussion in surveying previous work, neatly stepping across the bog of abbreviations that makes writing on cell and molecular biology so tough.

OS. Blair Hedges "Biogeography: The coelacanth of frogs"

(425, 669-670)
Does full justice to a cracking story, which at first sight seems of specialist interest only, taking in three disparate themes.

OSteve Blinkhorn "Neuroscience: Of mice and mentality" (424, 1004-1005)

Fizzy but properly cautious appraisal of the possible existence of a mouse version of $I Q$, all done in under a page of text.

John Harte "Ecology: Tail of death and resurrection" (424, 1006-1007) Brisk assessment, spiced with philosophical asides, of the standing of the neutral theory in ecology: not an easy topic.

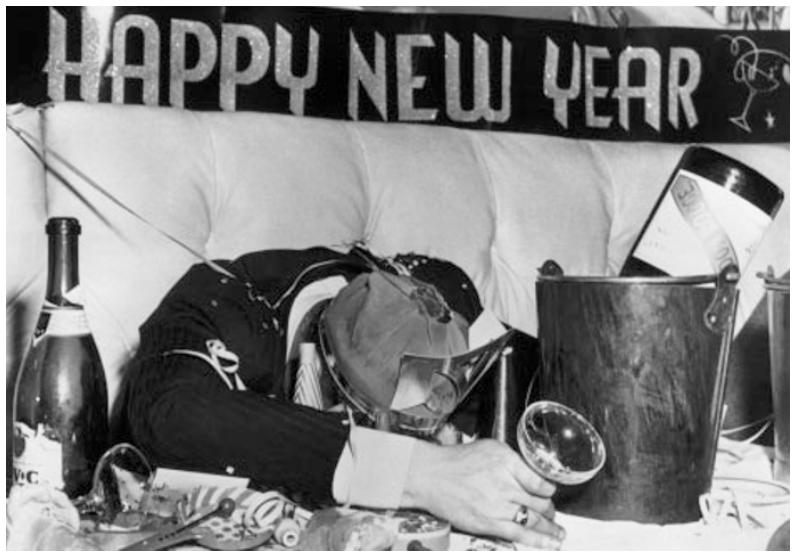

Toren Finkel "Ageing: A toast to long life" (425, 132-133) History used with wit to top and tail a succinct account of one angle on lifespan extension in yeast: never gets lost in the details (and includes a joke)
- Len A. Fisk "Planetary science: Over the edge?" (426, 21-22) Balanced, well-paced account of the adventures of Voyagers 1 and 2 at the edge of the Solar System, and the associated controversy. 